\title{
The role of social capital in COVID-19 deaths
}

\author{
Janaki Imbulana Arachchi ${ }^{1}$ and Shunsuke Managi $i^{1,2^{*}}$
}

\begin{abstract}
Background: The COVID-19 pandemic has shown a continuously increasing trend with a large variation in the number of COVID-19 deaths across countries. In response, many countries have implemented non pharmaceutical methods of intervention, such as social distancing and lockdowns. This study aims to investigate the relationship of four dimensions of social capital (community attachment, social trust, family bond, and security) and several control variables with COVID-19 deaths.

Methods: We retrieved data from open access databases and a survey. COVID-19 death-related data were collected from the website "Centre for Systems Science and Engineering (CSSE) at Johns Hopkins University". Social capital-related data were collected from a large-scale survey that included web-based and face-to-face surveys covering 100,956 respondents across all regions/provinces/states of 37 countries in 2017. Data regarding population density, number of hospital beds, and population aged 65 or older were retrieved from the World Development Indicators (WDIs). Data on country lockdowns were obtained from the website "National responses to the 2019-20 coronavirus pandemic". Linear regressions were applied to identify the relationship between social capital and COVID-19 deaths.

Results: We found that COVID-19 deaths were associated with social capital both positively and negatively. Community attachment and social trust were associated with more COVID-19 deaths, and family bond and security were associated with fewer deaths. COVID-19 deaths were positively associated with population density, ageing population, and interactions between four dimensions of social capital-related factors and the ageing population. Furthermore, the number of hospital beds and early lockdown policy were negatively associated with COVID-19 deaths.

Conclusions: The results indicate that the role of social capital in dynamically evolving threats, such as the current COVID-19 pandemic, is not always negative or positive. Therefore, people's behaviour should be changed to support countries' response to the COVID-19 threat.
\end{abstract}

Keywords: Social capital, COVID-19, Deaths, Pandemic

\footnotetext{
* Correspondence: managi@doc.kyushu-u.ac.jp

'Department of Civil Engineering, School of Engineering, Kyushu University,

744 Motooka, Nishi-ku, Fukuoka 819-0395, Japan

${ }^{2}$ Urban Institute, Kyushu University, 744 Motooka, Nishi-ku, Fukuoka 819-0395, Japan
}

(c) The Author(s). 2021 Open Access This article is licensed under a Creative Commons Attribution 4.0 International License, which permits use, sharing, adaptation, distribution and reproduction in any medium or format, as long as you give appropriate credit to the original author(s) and the source, provide a link to the Creative Commons licence, and indicate if changes were made. The images or other third party material in this article are included in the article's Creative Commons licence, unless indicated otherwise in a credit line to the material. If material is not included in the article's Creative Commons licence and your intended use is not permitted by statutory regulation or exceeds the permitted use, you will need to obtain permission directly from the copyright holder. To view a copy of this licence, visit http://creativecommons.org/licenses/by/4.0/ The Creative Commons Public Domain Dedication waiver (http://creativecommons.org/publicdomain/zero/1.0/) applies to the data made available in this article, unless otherwise stated in a credit line to the data. 


\section{Background}

Since the first report of severe acute respiratory syndrome coronavirus 2 (SARS-CoV-2) in China, coronavirus disease 2019 (COVID-19) [1] has spread as a pandemic affecting the whole world. More than 35 million people were infected, and more than 1 million deaths were reported by October 5, 2020. The COVID19 pandemic shows a continuously increasing trend and a great variation in infections and deaths across countries. Compared with other countries, most American and European countries have experienced a large number of COVID-19 cases and deaths [2]. In response to the rising numbers of cases and deaths, many countries have implemented non pharmaceutical methods of interventions, such as social distancing, case isolation and quarantine, contact tracing, and lockdowns [3-8]. The methods of controlling the pandemic and the causes behind the differences in cases and deaths among countries have not been identified despite the many related studies. These differences imply that not only clinical characteristics but also social contextual factors, such as social capital, determine COVID-19 deaths.

The concept of social capital was initially defined by sociologists in the 1980s as the aggregated value of connections between individuals and the norms of reciprocity developed from the network [9]. Several definitions of social capital have been advanced, most of which include similar concepts. Social capital is a commonly identified trait of social organization and includes trust between individuals, standards of correspondence and interpersonal connections that could increase the efficiency of society and create platforms that could be beneficial to many parties [10]. We turned to previous studies on social capital and health outcomes to make sense of the emerging relationships between social capital and COVID-19 deaths [11-18]. Although most social capital and health studies have considered the positive side of social capital [11-13, 18], studies related to the negative side of social capital on health have been growing [15-17]. Therefore, the relationship between social capital and health is a double-edged phenomenon [17]. An important problem that needs to be addressed is the connection between social capital and the prevalence of COVID-19-related deaths, based on existing studies on the relationship between social capital and health.

In the pandemic context, clinical studies have shown that COVID-19 mortality can occur due to age, smoking, obesity, lack of immunity, and hospital care, and it is commonly observed among patients with other diseases, such as diabetes and heart diseases [19-22]. However, clinical evidence alone is insufficient to propel the implementation of policies to reduce the number of COVID-19-related deaths, and certain studies related to social capital have attempted to fill the gap in the research on COVID-19. Several studies have concluded that the development and maintenance of different types of social ties influence the response to the COVID-19 pandemic [23]. A recent study analysed the positive association of COVID-19 deaths with social trust [24]. However, previous studies related to COVID-19 have not obtained similar results regarding social capital and COVID-19-related deaths.

This study aims to investigate the relationship of social capital-related factors/variables, including community attachment, social trust, family bond, and security, with several control variables and their influence on COVID19 deaths, hypothesizing that COVID-19 deaths can be explained more through social capital. Social capital can be measured in different dimensions, and in this study, the four factors of community attachment [25, 26], social trust [25, 27-29], family bond [30,31], and security [30, $32,33]$ were used to measure social capital based on previous studies. Moreover, we assume that relying on both prior pandemic and health studies of the positive relationship between social capital and health [33-35],all four factors may be negatively associated with COVID19-related deaths. We examined the association of social capital with COVID-19 deaths and additionally considered its association with the aged population and COVID-19 deaths. We further investigated the relationship of COVID-19 deaths with population density, aged population, number of hospital beds, and country lockdown as a proxy for government policy.

\section{Methods}

\section{Study design and data sources}

For this study, we used data from open access databases and a survey. We collected COVID-19-related data from the website "COVID-19 Dashboard by the Centre for Systems Science and Engineering (CSSE) at Johns Hopkins University" [2]. This website has complied data from several important sources, such as the World Health Organization (WHO), European Centre for Disease Prevention and Control (ECDC), and WorldoMeters, which have documented COVID-19 case numbers, death numbers, recovered numbers, active case numbers, testing rate, case-fatality ratio and incidence rate from 188 countries by country and province/state. We identified 35,157,350 COVID-19 cases with 1,037, 075 deaths at $11.00 \mathrm{AM}$ on October 05,2020 from the CSSE database.

Social capital data were collected from a large-scale web-based and face-to-face survey of 100,956 respondents across all regions/provinces/states of 37 countries in 2017. The web-based approach was predominantly used in this survey to avoid interviewer bias caused by arbitrary factors. We derived questions in the 
questionnaire based on the sociology and psychology literature. Additionally, we contacted a survey company in each country to translate the questionnaire into the native language and conduct the survey, and we carefully assessed the surveys to ensure the accuracy of responses through translations and multiple checks by native survey conductors. We used the data of a previous year (2017) instead of during the COVID-19 pandemic to measure social capital in each considered country to gain an understanding of society and people's behaviour in general conditions. Individuals' responses change due to unexpected incidents and information. Therefore, we used social capital data collected during stable conditions and checked the influence on unexpected risk events, such as COVID-19 deaths. Data regarding population density, hospital bed numbers, and population aged 65 or older were retrieved from the World Development Indicators (WDIs) [36]. Data on country lockdowns were obtained from the website "National responses to the 2019-20 coronavirus pandemic" [37].

The most recent WDI country data was available for 2018. After merging our survey data with COVID-19 data and WDI country-level data, the study sample consisted of 765,875 deaths in 37 countries. Among these countries, 8 countries, China, India, the USA, Indonesia, Brazil, Russia, Mexico, and Japan, were separated into provinces/states because they had the highest populations in the sample. Therefore, the total number of observations was 294. The sample countries and cumulative COVID-19 deaths are described in Supplementary Table S1.

\section{Measures}

COVID-19 deaths were measured as the number of deaths per square kilometre $\left(\mathrm{km}^{2}\right)$. The deaths per $\mathrm{km}^{2}$ were calculated by dividing the number of deaths by the land area $\mathrm{km}^{2}$ of 29 countries and the land area $\mathrm{km}^{2}$ of the provinces of the 8 most populous countries in the sample.

Social capital was measured by four factors adopted from previous studies, namely, community attachment, social trust, family bond, and security, and were ordinal variables. The four variables were assessed using a single question based on a previous study conducted among the general public [38]. Community attachment is one of the main independent variables in this analysis. The respondents were asked to measure their attachment to the neighbourhood/community in which they currently reside on a 5 -point Likert scale, where $1=$ not attached at all, $2=$ not really attached, $3=$ neither attached nor detached, $4=$ slightly attached, and $5=$ very attached. The average of all items was created, and a higher score indicated that the respondents displayed slight attachment to the community. Social trust is another main variable, and the respondents were asked to measure the importance they attached to "being able to believe people/organizations". Answers were rated on a 5-point Likert scale, where $1=$ not at all important, $2=$ not very important, $3=$ neither, $4=$ somewhat important, and $5=$ very important. The average of all items was created, and the high score indicated that to the respondents, social trust was somewhat important. To measure family bond, another main variable, the respondents were asked to measure their feelings about family relationships in the following question: "Do you feel that the relationship with family is important?" A negative answer was rated as 0 , and a positive answer was rated as 1 . The average of all items was created, and the high score indicated that the respondents considered the family relationship important. For the final main variable, security, the respondents were asked to measure the safety of their neighbourhood according to the question "Do you think the people in your neighbourhood are safe?" Answers were rated on a 5 -point Likert scale, where $1=$ do not know, 2 =very dangerous, $3=$ slightly dangerous, $4=$ moderately safe, and $5=$ very safe. The average of all items was created, and the high score indicated that respondents considered that the people in their neighbourhood were not safe. For further details, the survey questionnaire is provided in Supplementary Material 2.

Other explanatory variables are population density, population aged 65 or older, the interaction terms between population aged 65 or older and social capitalrelated factors, number of hospital beds, and country lockdown. Population density was measured by dividing the total population of each country by the land area $\mathrm{km}^{2}$ of 29 countries and the land area $\mathrm{km}^{2}$ of the provinces of the 8 most populous countries. The population aged 65 or older was measured by dividing the total population of each country by the land area $\mathrm{km}^{2}$ of 29 countries and the total population of the provinces of the 8 most populous countries. The number of beds was measured per 1000 people. Country lockdown was a dummy variable measured by the number of days before a shutdown/lockdown decision was made or a stay-athome order imposed after the first COVID-19 case was reported in China. If a country was locked down or a stay-at-home order was imposed after 50 days, it was called an early lockdown; if it was locked down after 100 days, it was called a late lockdown; and if a country was not locked down, it was referred to as having no lockdown. We used all the variables in log form except the number of beds and country lockdown to make the data conform more closely to the normal distribution and to improve the model fit.

\section{Statistical analysis}

Stata 16 software was used for all analyses. First, we conducted descriptive statistics to describe the centrality of 
the variables. Second, we conducted Pearson's correlation analysis to assess the associations between the variables considered in this study. For the correlation analysis, we employed Cohen's (1992) standard to determine whether the correlation coefficients were substantial, with $r=.01, .03$, and .05 representing small, medium, and large effect sizes, respectively [39]. Finally, we employed multiple linear regression to analyse the influence of various independent variables on COVID19 deaths, including community attachment, social trust, family bond, and security (to measure social capital), population density, population aged 65 or older, community attachment with population aged 65 or older, social trust with population aged 65 or older, family bond with population aged 65 or older, security with population aged 65 or older, and number of beds and country lockdown. In the multiple regression analyses, COVID19 deaths per $\mathrm{km}^{2}$ were the dependent variable, and the main explanatory variable was social capital. We checked the influence of some independent variables on the dependent variable in this paper. We employed the multiple regression model, an econometric model for testing whether explanatory variables significantly influence the dependent variable, in our analysis. We regressed eight multiple linear regression models with four social capital-related variables, and the other explanatory variables were added one by one. Prior to using multiple regression, simple linear regressions were applied to investigate the correlation between COVID-19 deaths and the four variables used to measure social capital. We divided the sample into two groups: all samples and only the provinces/states of 8 countries. The goal was to examine whether the relationship between COVID-19 deaths and social capital-related variables varied by country. The correlation coefficient and $p$-value of the coefficient for the social capital-related variables were calculated in the analyses of both groups.

\section{Results}

\section{Descriptive statistics}

Table 1 summarizes the means, SDs, medians and ranges of COVID-19 deaths per $\mathrm{km}^{2}$ and the regression covariates. For the 294 observations (29 countries and 264 provinces of 8 countries), the mean score for COVID-19 deaths per $\mathrm{km}^{2}$ was $0.09(\mathrm{SD}=0.54)$, meaning that the score of COVID-19 deaths per $\mathrm{km}^{2}$ was relatively low. Regarding the social capital-related factors, the respondents indicated that they were slightly attached to their community (3.71 out of 5), with a median response of 3.64 (IQR 3.38-3.94), and the respondents felt that being able to trust their society was somewhat important (4.53 out of 5), with a median response of 4.57 (IQR 4.40-4.69). Moreover, the respondents reported that they felt that relationships with family were important ( 0.90 out of 1$)$, with a median response of 0.92 (IQR 0.86-1), and they thought the people in their neighbourhood were slightly dangerous (2.95 out of 5), with a median response of 2.96 (IQR 2.77-3.21). The results for the mean and median of all four factors of social capital-related factors varied little. Furthermore, the mean score of population density was 540.47 ( $\mathrm{SD}=1793.92)$; the mean score of the population aged 65 or older per $\mathrm{km}^{2}$ was $42.77(\mathrm{SD}=146.77)$; and the mean score of the number of beds per 1000 people

Table 1 Descriptive statistics of model variables $(N=294)$

\begin{tabular}{|c|c|c|c|c|c|}
\hline Variables & Mean & SD & Median & Min & Max \\
\hline Covid-19 deaths per $\mathrm{km}^{2}$ & 0.09 & 0.54 & 0.01 & 0 & 7.17 \\
\hline \multicolumn{6}{|l|}{ Social Capital related factors } \\
\hline Community attachment (IQR) & 3.71 & 0.53 & $3.64(3.38-3.94)$ & 1 & 5 \\
\hline Social trust (IQR) & 4.53 & 0.30 & $4.57(4.40-4.69)$ & 1 & 5 \\
\hline Family bond (IQR) & 0.90 & 0.21 & $0.92(0.86-1)$ & 0 & 1 \\
\hline Security (IQR) & 2.95 & 0.33 & $2.96(2.77-3.21)$ & 1 & 5 \\
\hline \multicolumn{6}{|l|}{ Other explanatory variables } \\
\hline Population density & 540.47 & 1793.9 & 113 & 1 & 19,044 \\
\hline Population aged 65 or older per $\mathrm{km}^{2}$ & 42.77 & 146.77 & 6.18 & 0 & 1372.60 \\
\hline Community attachment*Population aged 65 or older per $\mathrm{km}^{2}$ (Aged65CA) & 154.70 & 557.46 & 24.45 & 0 & 4987.52 \\
\hline Social trust* Population aged 65 or older per km² (Aged65ST) & 188.70 & 656.45 & 28.58 & 0 & 6154.27 \\
\hline Family bond* Population aged 65 or older per km² (Aged65FB) & 42.19 & 158.30 & 5.47 & 0 & 1607.15 \\
\hline Security* Population aged 65 or older per km² (Aged65S) & 121.72 & 421.87 & 19.16 & 0 & 3895.95 \\
\hline Bed number per 1000 people & 4.28 & 4.21 & 2.22 & 0.53 & 13.05 \\
\hline Country lockdown & 2.04 & 0.97 & 2 & 1 & 3 \\
\hline
\end{tabular}

Note: Interquartile range in parentheses 
was $4.28(\mathrm{SD}=4.21)$, which was relatively low compared with the mean score ranging from 0.53 to 13.05 . However, the country lockdown policy showed that most of the countries decided to shut down/lockdown or impose a stay-at-home order 50 days after the report of the first COVID-19 case in China (2.04 out of 3).

\section{Simple regression analyses: the relationship between COVID-19 deaths per $\mathrm{km}^{2}$ and social capital}

The relationship between COVID-19 deaths per $\mathrm{km}^{2}$ and social capital-related factors is illustrated in Fig. 1. Figure 1a and $\mathrm{b}$ demonstrate that COVID-19 deaths per $\mathrm{km}^{2}$ were positively and significantly associated with community attachment for all samples $(r=0.27, p=$ $0.000)$ and for the provinces of 8 countries $(r=0.24, p=$ 0.000 ). Figure $1 \mathrm{c}$ and $\mathrm{d}$ also displays that the positive correlation between COVID-19 deaths per $\mathrm{km}^{2}$ and social trust was significant for all countries $(r=0.29, p=$ $0.000)$ and for the provinces of 8 countries $(r=0.32, p=$ $0.000)$. In contrast, Fig. 1e and $\mathrm{f}$ shows a negative and significant correlation between COVID-19 deaths per $\mathrm{km}^{2}$ and family bond for all countries $(r=-0.15, p=$ $0.014)$ and for the provinces of 8 countries $(r=-0.21$, $p=0.001)$. Finally, Fig. $1 \mathrm{~g}$ and $\mathrm{h}$ reveals a negative correlation between COVID-19 deaths per $\mathrm{km}^{2}$ and security for all countries $(r=-0.07, p=0.231)$ and for the provinces of 8 countries $(r=-0.06, p=0.307)$.

\section{Multiple regression analyses}

The results of multiple linear regressions for predicting COVID-19 deaths per $\mathrm{km}^{2}$ are shown in Table 2. According to our aim, we included social capital-related factors for all specifications (1-8) to check the robustness of the predictions of the social capital-related factors. In columns 1-7, we included the other explanatory variables one-by-one along with the social capital-related factors. In columns 3-6, we included social capitalrelated factors with the population aged 65 or older as interaction terms. In column 8 , we included all explanatory variables simultaneously in the regression model.

Among the social capital-related factors, two factors, community attachment and social trust, were associated with more COVID-19 deaths per $\mathrm{km}^{2}$. In contrast, two other factors, family bond and security, were associated with fewer COVID-19 deaths per $\mathrm{km}^{2}$ in all specifications. Other explanatory variables, population density and population aged 65 or older per $\mathrm{km}^{2}$, were associated with more COVID-19 deaths per $\mathrm{km}^{2}$; all interaction terms between population aged 65 or older and social capital-related factors were associated with more COVID-19 deaths per $\mathrm{km}^{2}$. One additional bed per 1000 people was associated with fewer COVID-19 deaths per $\mathrm{km}^{2}$. Early lockdown policies were associated with fewer COVID-19 deaths than late lockdown policy.

\section{Robustness analyses}

As robustness checks, although we included other explanatory variables with social capital-related factors in several multiple regressions, the sign of the influence of social capital-related factors on COVID-19 deaths was not changed. Furthermore, the robust standard error implies that there was no heteroscedasticity, and diagnostic tests confirmed normality and no multicollinearity in the regressions. In addition, we tested the correlation between COVID-19 deaths per $\mathrm{km}^{2}$ and social capitalrelated factors by the 8 most populous countries separately. Most of the results were similar to those in Fig. 1. The results are presented in Supplementary Fig. S1.

\section{Discussion}

To the best of our knowledge, this is the first systematic study to examine the impact of social capital on COVID-19 deaths. Multiple regression analysis revealed that, as we hypothesized, COVID-19 deaths are associated with social capital-related factors in two dimensions. Community attachment and social trust were associated with increased COVID-19 deaths, while family bond and security, were associated with reduced COVID-19 deaths in this study. The key findings of the study are discussed below.

In this study, we found that a one percentage point increase in average community attachment and social trust are associated with a $4 \%$ and a $14 \%$ (on average) increase in COVID-19 deaths, respectively. In contrast, a one percentage point increase in average family bond and security are associated with a $1 \%$ and a $4 \%$ (on average) reduction in COVID-19 deaths, respectively. Therefore, the positive impact of social capital-related factors was larger than the negative impact on COVID-19 deaths in all specifications. In terms of correlation coefficients, similar conclusions were observed at the country level as well as at the province level for 8 countries (Fig. 1). Although we expected to find negative associations, given the prior evidence of a positive link between social capital and health [e.g., [12-14, 18]], community attachment and social trust were positively associated with COVID19 deaths. These findings are consistent with the fact that a low level of institutional trust interferes with endeavours to contain transmission through physical distancing [40], and societies with high social trust might be more vulnerable to deception about the severity of COVID-19, counterfeit treatments, and contemptuous perspectives on physical distancing [41]. In addition, family bond and security were negatively associated with COVID-19 deaths. These findings align with previous findings that family social capital has several dimensions, with its components showing a clear relationship with health [31], and that neighbourhood social capital influences health communication [32, 33, 42]. These results 


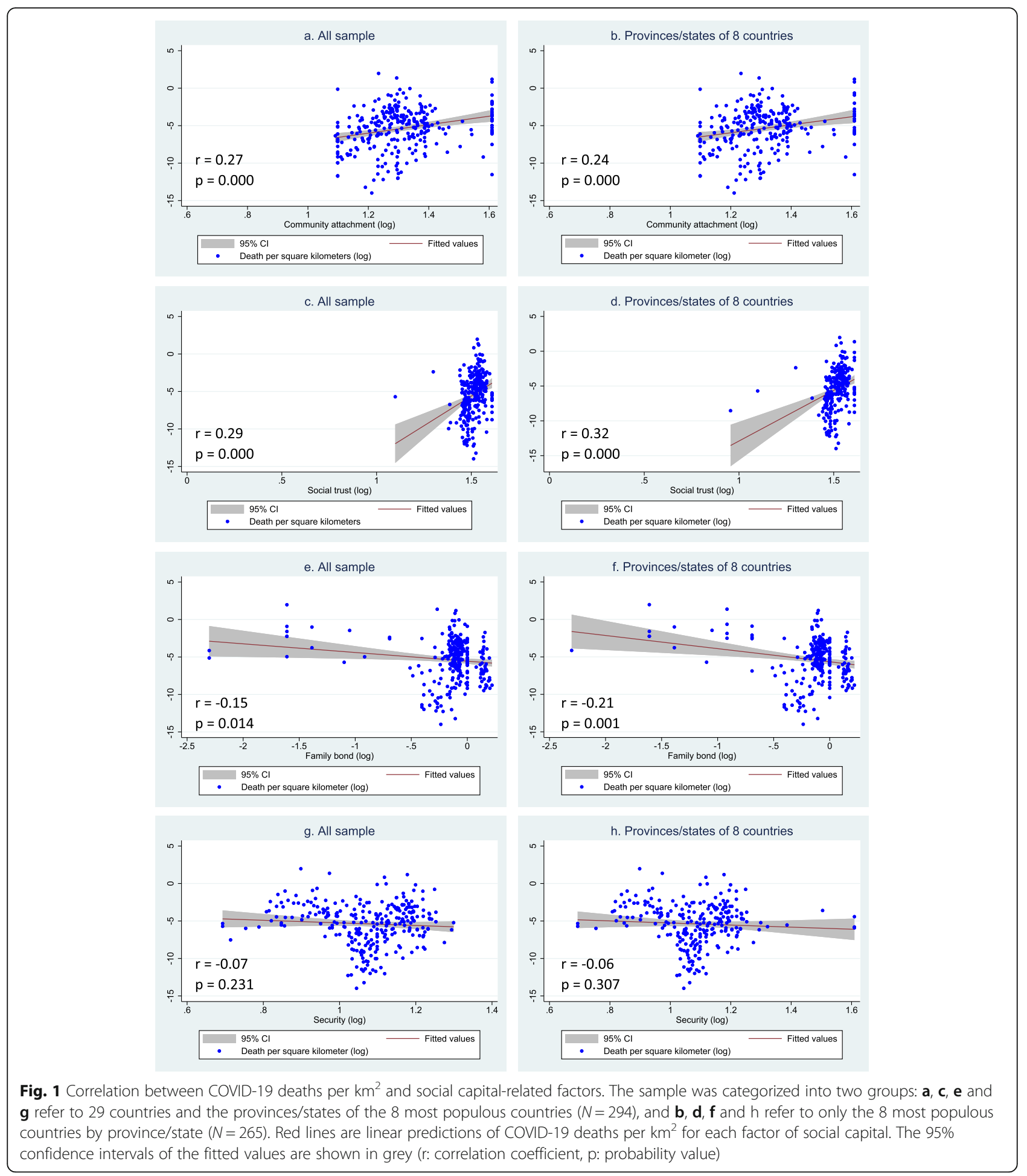

suggest that social capital is a double-edged phenomenon [17] and does not always positively or negatively affect health [24].

Population density was found in this study to be associated with more COVID-19 deaths per $\mathrm{km}^{2}$, which supports previous study findings that the population density is associated with the COVID-19 outbreak and related deaths [43-45]. Recent clinical studies have observed that older people have a high COVID-19 mortality risk [19, 21, 22]. Our study also confirmed that a high population aged 65 or older was significantly associated with high COVID-19 
Table 2 Multiple regression results for COVID-19 deaths

\begin{tabular}{|c|c|c|c|c|c|c|c|c|}
\hline Variables & 1 & 2 & 3 & 4 & 5 & 6 & 7 & 8 \\
\hline Intercept & $\begin{array}{l}-41.974^{\mathrm{a}} \\
(6.606)\end{array}$ & $\begin{array}{l}-33.473^{a} \\
(6.216)\end{array}$ & $\begin{array}{l}-33.473^{a} \\
(3.552)\end{array}$ & $\begin{array}{l}-33.473^{a} \\
(6.216)\end{array}$ & $\begin{array}{l}-33.473^{a} \\
(6.216)\end{array}$ & $\begin{array}{l}-33.473^{a} \\
(6.215)\end{array}$ & $\begin{array}{l}-19.645^{a} \\
(5.431)\end{array}$ & $\begin{array}{l}-21.416^{a} \\
(4.623)\end{array}$ \\
\hline $\begin{array}{l}\text { Log (Community } \\
\text { attachment) }\end{array}$ & $3.767^{\mathrm{a}}(1.139)$ & $4.862^{\mathrm{a}}(1.019)$ & $4.181^{\mathrm{a}}(1.026)$ & $4.862^{a}(1.019)$ & $4.862^{\mathrm{a}}(1.019)$ & $4.862^{\mathrm{a}}(1.019)$ & $3.581^{\mathrm{a}}(1.188)$ & $2.273^{b}(0.997)$ \\
\hline Log (Social trust) & $\begin{array}{l}21.007^{\mathrm{a}} \\
(4.216)\end{array}$ & $15.859^{\mathrm{a}}(3.869)$ & $\begin{array}{l}15.859^{\mathrm{a}} \\
(3.869)\end{array}$ & $\begin{array}{l}15.178^{\mathrm{a}} \\
(3.855)\end{array}$ & $15.859^{\mathrm{a}}(3.869)$ & $\begin{array}{l}15.859^{\mathrm{a}} \\
(3.869)\end{array}$ & $8.285^{b}(3.351)$ & $\begin{array}{l}10.769^{\mathrm{a}} \\
(2.831)\end{array}$ \\
\hline Log (Family bond) & $\begin{array}{l}-0.858^{a} \\
(0.308)\end{array}$ & $\begin{array}{l}-1.485^{a} \\
(0.326)\end{array}$ & $\begin{array}{l}-1.485^{\mathrm{a}} \\
(0.326)\end{array}$ & $\begin{array}{l}-1.485^{\mathrm{a}} \\
(0.326)\end{array}$ & $\begin{array}{l}-2.166^{a} \\
(0.329)\end{array}$ & $\begin{array}{l}-1.485^{\mathrm{a}} \\
(0.326)\end{array}$ & $\begin{array}{l}-0.570^{c} \\
(0.342)\end{array}$ & $\begin{array}{l}-0.345^{c} \\
(0.191)\end{array}$ \\
\hline Log (Security) & $\begin{array}{l}-2.983^{\mathrm{a}} \\
(0.961)\end{array}$ & $\begin{array}{l}-3.384^{\mathrm{a}} \\
(0.882)\end{array}$ & $\begin{array}{l}-3.384^{\mathrm{a}} \\
(1.035)\end{array}$ & $\begin{array}{l}-3.384^{\mathrm{a}} \\
(0.882)\end{array}$ & $\begin{array}{l}-3.384^{\mathrm{a}} \\
(0.882)\end{array}$ & $\begin{array}{l}-4.065^{\mathrm{a}} \\
(0.882)\end{array}$ & $\begin{array}{l}-3.586^{\mathrm{a}} \\
(1.096)\end{array}$ & $\begin{array}{l}-5.096^{\mathrm{a}} \\
(0.849)\end{array}$ \\
\hline Log (population density) & $0.623^{a}(0.075)$ & & & & & & & $0.357^{\mathrm{a}}(0.101)$ \\
\hline Log (Aged65 or older) & & $0.681^{\mathrm{a}}(0.049)$ & & & & & & $0.612^{\mathrm{a}}(0.087)$ \\
\hline Log (Aged65CA) & & & $0.681^{\mathrm{a}}(0.049)$ & & & & & \\
\hline $\log ($ Aged65ST) & & & & $0.681^{\mathrm{a}}(0.049)$ & & & & \\
\hline Log (Aged65FB) & & & & & $0.681^{a}(0.049)$ & & & \\
\hline Log (Aged65S) & & & & & & $0.681^{\mathrm{a}}(0.049)$ & & \\
\hline $\begin{array}{l}\text { Bed number per } 1000 \\
\text { people }\end{array}$ & & & & & & & $\begin{array}{l}-0.013 \\
(0.752)\end{array}$ & $\begin{array}{l}-0.228^{a} \\
(0.036)\end{array}$ \\
\hline \multicolumn{9}{|l|}{ Country lockdown } \\
\hline 2 Early lockdowns & & & & & & & $\begin{array}{l}-3.843^{\mathrm{a}} \\
(0.583)\end{array}$ & $\begin{array}{l}-1.241 \\
(0.763)\end{array}$ \\
\hline 3 Late lockdowns & & & & & & & $1.712^{\mathrm{a}}(0.331)$ & $0.947^{\mathrm{a}}(0.259)$ \\
\hline$R^{2}$ & 0.29 & 0.52 & 0.52 & 0.52 & 0.52 & 0.52 & 0.37 & 0.67 \\
\hline Adj. $R^{2}$ & 0.28 & 0.51 & 0.51 & 0.51 & 0.51 & 0.51 & 0.36 & 0.66 \\
\hline N & 278 & 276 & 276 & 276 & 276 & 276 & 278 & 277 \\
\hline
\end{tabular}

Note: The dependent variable was Covid-19 deaths per $\mathrm{km}^{2}$ (log). Robust standard error in parentheses. ${ }^{\mathrm{a}}{ }^{\mathrm{b}}$ and ${ }^{\mathrm{c}}$ denote statistical significance at the 99,95 and $90 \%$ level, respectively

deaths. In addition, the interaction terms of social capital-related factors with the population aged 65 or older appeared to be associated with more deaths from COVID-19. The number of hospital beds was negatively and significantly associated with COVID19 deaths. This finding implies that the hospital bed is a critical input in treating COVID-19-infected patients [46]. In addition, the early lockdown policy was a more effective response reducing COVID-19 deaths than the no lockdown and late lockdown policies [7, 47].

\section{Strengths and limitations}

There are some limitations in this study. First, this study included only 37 countries based on our survey data. However, our sample included the countries reporting the highest COVID-19 infections and deaths, including the USA, India, Brazil, Russia, and Spain. Second, we selected only a limited number of factors that potentially determine COVID-19 deaths in a country. To improve the prediction accuracy, other factors may also be included in future studies.
Finally, although COVID-19 data were available at the country level as well as at the province level, there was a lack of public data for other demographic variables in certain countries. Additional weaknesses in this study include the limited sample size. It is important to cover many countries when conducting a global analysis, even though we covered 37 countries with different cultures and demographic characteristics. Furthermore, social capitalrelated factors can change over time, and the use of more years of data can help identify those changes, while our study addresses only the current state of social capital in the considered countries. Even though this study has come limitations and weaknesses, it covers 37 countries with a significant number of observations and different demographic characteristics. Furthermore, while many previous studies have discussed social capital in different dimensions, social capital has not been investigated with regard to COVID-19. Therefore, the results of this study can contribute to future pandemic-related policymaking at the country level. 


\section{Conclusion}

In response to the rising numbers of COVID-19 cases and deaths, most countries have implemented interventions to control the pandemic until a vaccine is developed. It is important to identify social contextual factors associated with the health impacts of COVID-19 to support public health policy.

In summary, our analysis found that social capitalrelated factors were associated with COVID-19 deaths in two dimensions. Community attachment and social trust were associated with more COVID-19-related deaths, while family bond and security were associated with fewer COVID-19-related deaths. In addition, higher COVID-19 deaths were associated with higher population density, an ageing population, fewer hospital beds, and lower government effectiveness. Social capitalrelated factors show both positive and negative effects on COVID-19 deaths, demonstrating a dynamic role of social capital and indicating that social capital does not always affect health positively or negatively. From this analysis, we conclude that social determinants of health are significantly affected by dynamically evolving threats, such as the current COVID-19 pandemic. People's behaviours should be changed to support countries' response to the COVID-19 threat.

\section{Abbreviations}

COVID-19: Coronavirus disease 2019; SARS-CoV-2: Severe acute respiratory syndrome coronavirus 2; CSSE: Centre for systems science and engineering: WHO: World health Organization; ECDC: European centre for disease prevention and control; WDIs: World development indicators; SD: Standard deviation; IQR: Interquartile range

\section{Supplementary Information}

The online version contains supplementary material available at https://doi. org/10.1186/s12889-021-10475-8

Additional file 1.

Additional file 2 .

\section{Acknowledgements}

Not applicable.

\section{Authors' contributions}

JIA conducted analysis, wrote manuscript and produced tables and Figs. SM formulated the research idea and supervision. All authors read and approved the final manuscript.

\section{Funding}

This work is supported by the following Grant in Aid from the Ministry of Education, Culture, Sports,Science and Technology in Japan (MEXT): Grant in Aid (20H00648), Ministry of Environment, Japan (1-2001). Any opinions, findings, and conclusions expressed in these 20 materials are those of the authors and do not necessarily reflect the views of the agencies.

\section{Availability of data and materials}

This study is used both open access data and survey data. For Covid-19 deaths related data, we used the dataset maintained by the Centre for Systems Science and Engineering (CSSE) at Johns Hopkins University: https:// coronavirus.jhu.edu/map.html. Data regarding population density, hospital beds numbers, and population age 65 or older, was retrieved from the World
Development Indicators: https://datatopics.worldbank.org/worlddevelopment-indicators/. Data on country lockdown was obtained from the website "National responses to the 2019-20 coronavirus pandemic": https:// en.wikipedia.org/wiki/National_responses to the COVID-19 pandemic. Social capital data was collected from a large-scale survey of 100,956 respondents across 37 countries that including web-based and face-to-face surveys covering all regions/provinces/states of 37 countries in 2017. Survey data is available from the corresponding author on reasonable request.

\section{Declarations}

\section{Ethic approval and consent to participate}

The undisclosed review committee for Kyushu University, Japan reviewed and provided ethical approval for this research. All procedures performed in this study were in accordance with the ethical standards. The survey was used both web-based and face-to-face surveys methods. At the beginning of each interview and web-survey, respondents were informed about the purpose of the survey and their right to voluntarily participate. All participants provided informed consent prior to response the questionnaire.

\section{Consent for publication}

Not applicable.

\section{Competing interests}

The authors declare that they have no known competing financial interests or personal relationships that could have appeared to influence the work reported in this paper.

Received: 29 November 2020 Accepted: 10 February 2021 Published online: 03 March 2021

\section{References}

1. Zhu N, Zhang D, Wang W, Li X, Yang B, Song J, et al. A novel coronavirus from patients with pneumonia in China, 2019. N Engl J Med. 2020;382:72733.

2. Johns Hopkins University \& Medicine, Coronavirus Resource Center, Maryland. 2020. https://coronavirus.jhu.edu/map.html. Accessed 5 Oct 2020

3. Nicola M, O'Neill N, Sohrabi C, Khan M, Agha M, Agha R. Evidence based management guideline for the COVID-19 pandemic - review article. Int J Surg. 2020;77:206-16.

4. Hellewell J, Abbott S, Gimma A, Bosse NI, Jarvis Cl, Russell TW, et al. Feasibility of controlling COVID-19 outbreaks by isolation of cases and contacts. Lancet Glob Heal. 2020;8:e488-96.

5. Mattioli AV, Ballerini Puviani M, Nasi M, Farinetti A. COVID-19 pandemic: the effects of quarantine on cardiovascular risk. Eur J Clin Nutr. 2020;74:852-5.

6. Flaxman S, Mishra S, Gandy A, Unwin HJT, Mellan TA, Coupland H, et al. Estimating the effects of non-pharmaceutical interventions on COVID-19 in Europe. Nature. 2020:584:257-61.

7. Pulla P. Covid-19: India imposes lockdown for 21 days and cases rise. BMJ 2020;368 http://dx.doi:https://doi.org/10.1136/bmj.m1251.

8. Yoo S, Managi S. Global mortality benefits of COVID-19 action. Technol Forecast Soc Change. 2020; doi.org/https://doi.org/10.1016/j.techfore.202 0.120231.

9. Coleman JS. Social Capital in the Creation of human capital. Am J Sociol. 1988:94:S95-120.

10. Kawachi I, Kennedy BP, Glass R. Social capital and self-rated health: a contextual analysis. Am J Pub Heal. 1999:8:1187-93.

11. Murayama H, Fujiwara $Y$, Kawachi I. Social capital and health: a review of prospective multilevel studies. J Epidemiol. 2012;22:179-87.

12. Harpham T, Grant E, Thomas E. Measuring social capital within health surveys: key issues. Health Policy Plan. 2002;17:106-11.

13. Hawe P, Shiell A. Social capital and health promotion: a review. Soc Sci Med. 2000:51:871-85.

14. Kabayama M, Watanabe C, Ryuno H, Kamide K. Positive and negative associations of individual social capital factors with health among community-dwelling older people. Geriatr Gerontol Int. 2017;17:2427-34

15. Moore S, Daniel M, Gauvin L, Dubé L. Not all social capital is good capital. Heal Place. 2009;15:1071-7.

16. Takakura M. Relations of participation in organized activities to smoking and drinking among Japanese youth: contextual effects of structural social capital in high school. Int J Public Health. 2015;60:679-89. 
17. Villalonga-Olives E, Kawachi I, et al. Soc Sci Med. 2017;194(October):105-27.

18. Ehsan A, Klaas HS, Bastianen A, Spini D. Social capital and health: a systematic review of systematic reviews. SSM - Popul Heal. 2019. https://doi. org/10.1016/j.ssmph.2019.100425.

19. Zhou F, Yu T, Du R, Fan G, Liu Y, Liu Z, et al. Clinical course and risk factors for mortality of adult inpatients with COVID-19 in Wuhan, China: a retrospective cohort study. Lancet. 2020;395:1054-62.

20. Wang D, Hu B, Hu C, Zhu F, Liu X, Zhang J, et al. Clinical characteristics of 138 hospitalized patients with 2019 novel coronavirus-infected pneumonia in Wuhan, China. J Am Med Assoc. 2020;323:1061-9.

21. Chen T, Wu D, Chen H, Yan W, Yang D, Chen G, et al. Clinical characteristics of 113 deceased patients with coronavirus disease 2019. BMJ. 2020;368: m1295.

22. Yin Q, Fu Z, Xie J, Yang J, Li F, Zhu W, et al. Analysis of Risk Factors of Severe COVID-19 Patients. 2020; doi.org/https://doi.org/10.21203/rs.3.rs-232 $72 / \mathrm{v} 2$.

23. Pitas N, Ehmer C. Social Capital in the Response to COVID-19. Am J Health Promot. 2020. https://doi.org/10.1177/0890117120924531.

24. Elgar FJ, Stefaniak A, Wohl MJA. The trouble with trust: time-series analysis of social capital, income inequality, and COVID-19 deaths in 84 countries. Soc Sci Med. 2020. https://doi.org/10.1016/j.socscimed.2020.113365.

25. Clark WAV, Yi D, Huang Y. Subjective well-being in China's changing society. Proc Natl Acad Sci U S A. 2019:116:16799-804.

26. Tsurumi T, Imauji A, Managi S. Relative income, community attachment and subjective well-being: evidence from Japan. Kyklos. 2019;72:152-82.

27. Ram R. Social capital and happiness: additional cross-country evidence. J Happiness Stud. 2010;11:409-18.

28. Bjørnskov C. Social capital and happiness in the United States. Appl Res Qual Life. 2008;3:43-62.

29. Rodríguez-pose A, Von Berlepsch V. Social capital and individual happiness in Europe. J Happiness Stud. 2012;15:357-86.

30. Helliwell JF, Putnam RD. The social context of well-being. Philos Trans R Soc B Biol Sci. 2004;359:1435-46.

31. Alvarez EC, Kawachi I, Romani JR. Family social capital and health - a systematic review and redirection. Sociol Heal IIIn. 2017;39:5-29.

32. Mohnen SM, Groenewegen PP, Völker B, Flap H. Neighborhood social capital and individual health. Soc Sci Med. 2011;72:660-7.

33. Jung $M$, Lin L, Viswanath $K$. Associations between health communication behaviors, neighborhood social capital, vaccine knowledge, and parents' H1N1 vaccination of their children. Vaccine. 2013;31:4860-6.

34. Chuang YC, Huang YL, Tseng KC, Yen CH, Yang LH. Social capital and health-protective behavior intentions in an influenza pandemic. PLoS One. 2015;10:1-14.

35. Rönnerstrand B. Social capital and immunisation against the 2009 a(H1N1) pandemic in Sweden. Scand J Public Health. 2013:41:853-9.

36. 19Bank, T.W. World Developmenr Indicators. 2020. http://datatopics.worldba nk.org/world-development-indicators/. Accessed 25 Sept 2020.

37. National responses to the COVID-19 pandemic. Government responses to the outbreak. 2020. https://en.wikipedia.org/wiki/National_responses_to_ the_COVID-19_pandemic. Accessed 5 Oct 2020.

38. Werner P, Goldberg S, Mandel S, Korczyn AD. Gender differences in lay persons' beliefs and knowledge about Alzheimer's disease (AD): a national representative study of Israeli adults. Arch Gerontol Geriatr. 2013;56:400-4.

39. Cohen J. A power primer. Psychol Bull. 1992;112:155-9.

40. Dezecache G, Frith $C D$, Deroy O. Pandemics and the great evolutionary mismatch. Curr Biol. 2020;30:R417-9.

41. Zmerli S. Social capital and norms of citizenship: an ambiquous relationship? Am Behav Sci. 2010;53:657-76.

42. Sampson RJ. Neighbourhood-level context and health: lessons from Sociology. In: Kawachi I, Berkman LF, editors. Neighbourhoods and health. New York: Oxford University Press; 2003. p. 132-46.

43. Rocklöv J, Sjödin H. High population densities catalyse the spread of COVID19. J Travel Med. 2020;27:1-2

44. Bhadra A, Mukherjee A, Sarkar K. Impact of population density on Covid 19 infected and mortality rate in India. medRxiv. 2020; doi.org/https://doi.org/1 0.1101/2020.08.21.20179416
45. Coşkun H, Yıldırım N, Gündüz S. The spread of COVID-19 virus through population density and wind in Turkey cities. Sci Total Environ. 2021. https://doi.org/10.1016/j.scitotenv.2020.141663.

46. Remuzzi A, Remuzzi G. COVID-19 and Italy: what next? Lancet. 2020;395: $1225-8$.

47. lacobucci G. Covid-19: UK lockdown is "crucial" to saving lives, say doctors and scientists. BMJ. 2020;368:m1204. https://doi.org/10.1136/bmj.m1204.

\section{Publisher's Note}

Springer Nature remains neutral with regard to jurisdictional claims in published maps and institutional affiliations.
Ready to submit your research? Choose BMC and benefit from:

- fast, convenient online submission

- thorough peer review by experienced researchers in your field

- rapid publication on acceptance

- support for research data, including large and complex data types

- gold Open Access which fosters wider collaboration and increased citations

- maximum visibility for your research: over $100 \mathrm{M}$ website views per year

At BMC, research is always in progress.

Learn more biomedcentral.com/submissions 